\title{
Chemical Composition antibacterial and antioxidant activity of the essential oils of Amomum subulatum by using Microwave extraction comparison with hydro distillation
}

\author{
Sekar Nethi ${ }^{1}$ and Prashant Mande ${ }^{2}$ \\ ${ }^{1}$ Affiliation not available \\ ${ }^{2}$ Institute of Chemical Technology, Mumbai
}

April 28, 2020

\begin{abstract}
Microwave assisted hydrodistillation (MAHD) and conventional hydrodistillation techniques were compared in the extraction of essential oils from Amomum subulatum seeds. The time required for MAHD method (70 min) is lesser than that for HD method $(4 \mathrm{hr})$. There is a slight increase in the yield of extracted oil in MAHD method (3.35\%) compared to HD (3\%). GC-MS results show that MAHD extracted essential oil was wealthier in oxygenated compounds. 1, 8-Cineole was found to be a major compound in case of both the essential oil, followed by $\alpha$-pinene. In MAHD the percentage of the major oxygenated monoterpene (1, 8- cineol) slightly increases from $88 \%$ to $89 \%$ as compared to hydrodistillation. Contrarily to this, the percentage of monoterpene hydrocarbon were decreased in MAHD than HD extracted oil. MAHD and HD extracted oils show good antibacterial activities against gram-negative and gram-positive bacteria. MAHD extracted oil shows better antibacterial activity than HD extracted against both gram positive and gram-negative bacteria. 2, 2-diphenyl-1-picrylhydrazyl $\left(\mathrm{DPPH}^{*}\right)$ radical scavenging antioxidant activities show that MAHD extract has better inhibition percentage than HD extract, and the IC50 value of MAHD was less than HD extracted oil.
\end{abstract}

\section{Introduction}

Amomum subulatum Roxb (Zingiberaceae), commonly known as large cardamom, is a perennial herbaceous plant with subterranean rhizomes which produces several leafy shoots and panicles [1][2]. It contains 1.95 to $3.23 \%$ of essential oil having typical characteristic flavor and possesses stimulant, stomachic, alexipharmic and astringent effects[3][4][5].

From ancient time spices are consumed in most of the countries.[5][6] Consumption of spices is based on the common assumption that they are related to taste and aroma[7][6][8]. The major constituent of large cardamom essential oil is 1, 8-cineole (35-80\%) while the content of $\alpha$-pinene is low (traces to five percent)[2][9][10]. Beyond their taste and smell, the recent scientific studies have proved that they have biological activities like analgesic, anti-inflammatory, antimicrobial, antimicrobial, antioxidant, antiulcer, cardioadaptogen, antidiabetic and hypolipidemic activities[5]. Continuous consumption of black cardamom leads to enhancement in fibrinolytic activity, total antioxidant status, and alteration in lipid profile in patients with ischemic heart diseases (IHD)[11][5].

Traditionally essential oil is obtained by homogenization, filtration/ centrifugation, steam-distillation, hydrodistillation, solvent, and Soxhlet extraction methods[12][13][13][14]. These methods have certain disadvantages such as the risk of thermal degradation of thermolabile active compounds as it usually requires long extraction time, also these methods consume more solvents and sometimes have lower efficiency[15][14][16]. 
Several novel extraction techniques have been introduced and studied in the past years, most of which were better in terms of the period of extraction, efficiency, and usage solvent than the traditional techniques[14]. The new extraction techniques available are microwave assisted hydrodistillation extractions (MAHD), supercritical fluid extraction (SFE), and pressurized solvent extraction (PSE)[13][17].

The advantages in case MAHD are saving of extraction time and solvents, selectivity, lessening environmental influence by emitting less $\mathrm{CO}_{2}$ in the atmosphere and controllable heating process which make MAHD as an important alternative extraction technique particularly in extracting biological materials[18][19][12].

The aims of this study are to investigate the potential of MAHD for the extraction of essential oil from seeds of Amomum subulatum and optimise the factors responsible for a good yield. The optimisation of the operating parameters was done. Besides this, we did a comparison between essential oil obtained by HD and MAHD in terms of the time required for extraction, the composition of extracted oil and the yield. We have also studied the antimicrobial and antioxidant activities of oils extracted by both the methods.

Material and methods

Materials

The large cardamom (Amomum subulatum ) was obtained from retail organic food stores. The standard bacterial strain of Escherichia coli (ATCC 8739) and Staphylococcus aureus (ATCC 25923) for testing the antimicrobial activity were procured from the National Collection of Industrial Microorganisms (NCIM), Pune, India and were maintained on nutrient agar slants and stored at $4{ }^{\circ} \mathrm{C}$ along with regular subculturing every two months. 2, 2-Diphenyl-1-picrylhydrazyl (DPPH) for the antioxidant study is procured from Alfa Aesar.

\section{Hydrodistillation}

The essential oil was extracted from seeds of cardamom by hydrodistillation. 100g of black cardamom seeds and $200 \mathrm{ml}$ of distilled water were taken in a flat bottom flask and submitted to hydrodistillation for $4 \mathrm{~h}$ using a Clevenger-type apparatus[1]. The Oil was pale yellow in color. The essential oil was collected, dried over anhydrous sodium sulfate and stored at $4^{0} \mathrm{C}$ in the sealed amber vial until further study.

\section{Microwave-assisted extraction}

Microwave-assisted extraction was performed using microwave variable in $80 \mathrm{~W}$ increments fabricated by CATALYST. Schematic of the experimental arrangement is shown in fig. 1. In MAE procedure, $100 \mathrm{~g}$ of seeds of black cardamom were inserted into an extraction vessel along with $100 \mathrm{ml}$ of water which is connected to a Clevenger-type apparatus located outside the microwave oven. The essential oil was removed from the aqueous medium after a simple decantation and dried over anhydrous sodium sulfate and stored at $4^{0} \mathrm{C}$ in the sealed amber vial until further study.

$<$ Insert Figure 1 Schematic of the fabricated microwave and assembly used in this study >

\section{GC-MS Analysis}

A detailed chemical composition analysis of the essential oil of Amomum subulatum seeds was performed using GC-MS (thermo TRACE 1310 GC coupled with ISQ Series Single Quadrupole GC-MS) equipped with DB-5 MS fused silica capillary column (30 m x $0.25 \mathrm{~m}$ i.e., film thickness $0.25 \mu \mathrm{m})$. Helium was used as carrier gas at a constant flow rate of $1 \mathrm{ml} / \mathrm{min}$, splitless injection volume $0.1 \mathrm{ml}$, and injection temperature was set at $250 \mathrm{C}$, oven temperature progress from 60 to $280 \mathrm{C}$ at $2^{0} \mathrm{C} / \mathrm{min}$. An electron ionization system with ionization energy of $70 \mathrm{eV}$ was used for GC- MS detection. Identification of essential oil components was based on GC retention time on MS column compared with the mass spectral fragmentation patterns in MS database (National Institute of Standards and Technology).

\section{Optimization of parameters}


Essential oil's quality and quantity generally be influenced by the extraction techniques[20]. The optimization of the experimental conditions is a vital step in set up of ideal operating conditions for MAHD method, as different factors can have impact on the extraction method. In general, microwave power, extraction time, and temperature are considered to be the most important factors [21]. All the selected parameter studied using five levels. Microwave power ranges from 160-800 W (160W difference), time of extraction ranges from $50 \mathrm{~min}$ to $90 \mathrm{~min}$ and temperature from $70^{\circ} \mathrm{c}$ to $110^{\circ} \mathrm{c}$.

\section{Antibacterial activity}

To study antimicrobial effect, we have prepared sterile nutrient broth petri plate. The nutrient broth was prepared by dissolving $13 \mathrm{~g}$ of nutrient broth mixed with $28.8 \mathrm{~g}$ of nutrient agar in $1 \mathrm{~L}$ water[22]. The media was autoclaved and allowed to cool to $50{ }^{\circ} \mathrm{C}$. Then, $25 \mathrm{~mL}$ of this solution was poured onto the petri plates and allowed to be solidified at room temperature for 30 minutes. On the plates, wells were made into an agar layer with stainless steel bore of approximately $4-5 \mathrm{~mm}$ in diameter. Then $25 \mu \mathrm{L}$ of essential oil sample was loaded into the bore and the plates were kept for $24 \mathrm{~h}$ of incubation.

Antioxidant activity ( DPPH radical-scavenging activity)

The scavenging effect on the DPPH radical was determined by using the reported method[23][12]. The different concentrations such as 10, 15, 20 and $25 \mu \mathrm{l}$ of volatile essential oil in methanol $(1 \mathrm{ml})$ were added to $4 \mathrm{ml}$ of $0.004 \%$ methanolic solution of DPPH. The reaction mixture was shaken vigorously and incubated for $30 \mathrm{~min}$ in the dark. After $30 \mathrm{~min}$ of maturation at $30^{0} \mathrm{c}$, absorbance was measured at $517 \mathrm{~nm}$ by using spectrophotometer against a blank. The Same process was applied to the control (without having any sample) and standards (containing antioxidant ascorbic acid in place of essential oil) for comparison. The reduction in absorption arising out of the presence of sample was measured by comparing with the results of control experiment. All experiments were carried out in triplicates. The annihilation activity of free radicals i.e. \% DPPH scavenging effect was calculated using the following equation[24],

$\% \mathrm{I}=\left\{\left(\mathrm{A}_{0}-\mathrm{A}_{\mathrm{T}}\right) / \mathrm{A}_{0}\right\} \times 100$

Where $A_{0}$ is the absorbance of the control and $A_{T}$ is the absorbance of the test samples.

IC50 values were calculated by plotting the percentage of DPPH radical scavenging capacity against the concentration of essential oils (shown in fig.5). IC50 is the concentration required to inhibit $50 \%$ of DPPH free radicals [25][7].

\section{Results and discussion}

\section{Yield and extraction time}

The yield of essential oil obtained by MAHD extraction was $3.35 \%$ which is much better as compared to the oil extracted by HD method i.e. $3 \%$. The time required to extract the essential oil from Amomum subulatum seeds by HD method $(4 \mathrm{~h})$ is more than that of MAHD method $(70 \mathrm{~min})$. The lesser extraction time in MAHD is because of the fact that in microwave mass and heat transfer occur in the same direction[26][18]. In case of hydrodistillation, heat is transferred to the surface of the material by conduction, convection or radiation and into the interior of the material by thermal while in microwave extraction heat is manifested through their interaction with the sample[18][26]. This results in rapid heating and hence the time required is less.

\section{Composition of essential oil}

The constituents of the volatile oil extracted from Amomum subulatum were analyzed by GC-MS. Table 1 gives the results of GC-MS of extracted oil by MAHD and HD methods. It is seen that there is a total of five components in both the oils.

<Insert Table 1: Chemical composition of essential oils extracted by hydrodistillation (HD) and Microwave assisted hydrodistillation (MAHD) from Amomum subulatum seeds $>$ 
The compounds were identified as $\alpha$-pinene, $\beta$-pinene, 1, 8-cineol, terpinen-4-ol, and $\alpha$-terpineol. Results show that there is the dominance of oxygenated compound over the monoterpene hydrocarbons in essential oil extracted by both i.e. MAHD and HD methods. Presence of oxygenated compound in the essential oil is good as those are odoriferous and are mainly responsible for the characteristic aroma of the essential oil[27][28]. Essential oil obtained by MAHD is more concentrated in oxygenated monoterpenes - 1, 8-cineol (89.62), terpene-4-ol (1.42) and $\alpha$-terpineol (3.10) - as compared to essential oil by HD where the percentage of oxygenated monoterpenes are 88.75 (1, 8-cineol), 1.21 (terpene-4-ol) and 1.50 ( $\alpha$-terpineol). The composition of extracted essential oil by MAHD and HD methods reveals that there is a decrease in the percentage of monoterpene hydrocarbon and increase in oxygenated monoterpene. Increase in yield of the essential oil and greater proportion of oxygenated monoterpenes is possibly due to less thermal and hydrolytic impact as heating is very fast in case of MAHD as compared to HD and lesser use of water in MAHD than in HD[26][16]. Another reason may be as polar compound adsorbs microwave irradiation more radially than others[29][27]. In connection with above theory here we observed that 1, 8-cineol, terpene-4-ol, and $\alpha$-terpineol are more polar as compared to $\alpha$ and $\beta$-pinene.

\section{Optimization of Parameters}

\subsubsection{Effect of microwave power}

In the extraction of Callistemon citrinus skeels by MAHD microwave power is a key factor that influences the efficiency due to the interaction of microwave with the extraction material. Microwave powers of different wattage (160-800 W) level were studied for MAHD extraction of essential oils by keeping time 80 min and temperature $100^{\circ} \mathrm{c}$ constant. Each experiment was done twice, and the average was taken.

$<$ Insert Figure 2 Influence of microwave power on essential oil yield >

The outcomes of the trials are presented in fig. 2. The result illustrates that there is an increase in the yield of essential oil as we increase the microwave power from 160 to $800 \mathrm{~W}$ from 2.1 to $3.3 \%$ respectively. The increase in the yield with the increase in the microwave power is due to the rapid generation of heat in the sample material (mostly polar material in oil) with the absorption of microwave (Thakker, Parikh, \& Desai, 2016). We get the highest yield of $3.3 \%$ at the $800 \mathrm{~W}$ microwave power.

\subsubsection{Effect of extraction time}

Fig.3 shows that yield of extracted essential oil at different time interval where the microwave power $800 \mathrm{~W}$ and the temperature $100^{\circ} \mathrm{c}$ are kept constant. The rate of extraction at an initial stage of $50 \mathrm{~min}$ to 80 min increases rapidly from 2.5 to $3.3 \%$ and then no rises as we increase the time up to 90 min yield is 3.3 \%. This shows that more will be extraction time more is extraction yield. As we go from 80 min to 90 there no increase in this means that after some certain period the extraction yield was constant, which is well accordance with the previous studies (M.-T. Golmakani \& Rezaei, 2008; Man, Hamzah, Jamaludin, \& Abidin, 2012; Ranitha et al., 2014).

$<$ Insert Figure 3 Influence of extraction time on essential oil yield >

\subsubsection{Effect of temperature}

Fig. 4 shows the yield of extraction at different temperatures having the time and the microwave power was kept constant. The graph shows that the rate of extraction from $70^{\circ} \mathrm{c}$ to $80^{\circ} \mathrm{c}$ there is little increase in yield. As we go beyond $80^{\circ} \mathrm{c}$ the rate of increase in yield is more up to $100^{\circ} \mathrm{c}$, as we further increase the temperature there is no further improvement in the yield of extracted oil. Higher extracting temperature is gainful for extraction owed to the improved solubility. The system we used here is closed one and in a closed microwave system the temperature of the water in flask could be increased above the boiling point. The solubility of the essential oil is increased because of increase in temperature and the efficiency of extraction in enhance. higher temperature causes intermolecular interactions and have higher molecular motion. The higher temperature favours opening of the cell matrix and increases the availability of essential oil.

$<$ Insert Figure 4 Influence of temperature on essential oil yield $>$ 


\section{Antibacterial Study}

In vitro antibacterial study of essential oil extracted by both the methods was done against gram negative and gram-positive bacteria. Microbial growth inhibited by amomum subulatum seed oil extracted by MAHD and HD methods are shown in fig.5.

$<$ Insert Figure 5 Antibacterial activities of a: HD essential oil against E-coli b: HD essential oil against S. aureus c: MAHD essential oil against E-coli and d: MAHD essential oil against S. aureus>

Fig. 6 reveals that oils obtained by both methods have good antibacterial activity against Staphylococcus aureus and Escherichia coli. Zones of inhibition for microwave essential oil and hydrodistilled oil were respectively $1.5 \pm 0.2 \mathrm{~mm}$ and $1.1 \pm 0.2 \mathrm{~mm}$ in the case of Staphylococcus aureus. Similarly, in case of Escherichia coli were $1.2 \pm 0.2 \mathrm{~mm}$ and $1 \pm 0.2 \mathrm{~mm}$ respectively. In case of both gram-positive and gramnegative bacteria zone of inhibition of MAHD extracted oil was more as compared to that of HD extracted

oil. The higher antibacterial activity of MAHD extracted essential oil may be due to the higher amount of oxygenated compounds present[26].

$<$ Insert Figure 6: Zone of inhibition of MAHD and HD extracted essential oil against Escherichia coli and Staphylococcus aureus bacteria>

\section{Antioxidant activity}

In this study scavenging activity of both the essential oil was studied against DPPH. DPPH is a stable radical which shows higher absorption at 515nm[30][31].

$$
D P P H \bullet+A H \rightarrow D P P H-H+A \bullet
$$

Above reaction demonstrate that DPPH radially undergoes reduction by an antioxidant (AH)[30]. DPPH assay is a rapid, trustworthy and reproducible parameters for showing in vitro antioxidant activity of plant extracts because of the ease and convenience of reaction[25][30]. The studied essential oils were able to reduce the stable radical DPPH from deep violet to the light yellow color indicating their antioxidant activity[24][32].

\section{$<$ Insert Table 2: Antioxidant activity (Percent Inhibition) of essential oil in DPPH free radical scavenging activity $>$}

The assay result is presented as percentage inhibition of free radical in table 2 . The results reveal that the essential oil of black cardamom extracted by MAHD and HD methods show concentration-dependent antioxidant activity. The percentage inhibition goes from 54.43 to 74.44 and from 47.44 to 64.84 for MAHD and HD extracted essential oil respectively as we increase concentration from 10 to $25 \mu \mathrm{g} / \mathrm{ml}$. the percentage inhibition for MAHD and HD extracted oil was significantly lower as compared to standard ascorbic acid (AA).

$<$ Insert Figure 7 Plot of percentage of DPPH radical scavenging capacity against the concentration of essential oils By MAHD and HD methods $>$

The IC50 values which we get from the plot of percentage of DPPH radical scavenging capacity against the concentration of essential oils (Fig. 7) for MAHD and HD extracted essential oils are $7.5 \mu \mathrm{g} / \mathrm{ml}$ and 12.71 $\mu \mathrm{g} / \mathrm{ml}$ respectively. The percentage inhibition and IC50 values of the essential oil extracted by MAHD and HD techniques show that MAHD extracted oil has better antioxidant activity than the HD extracted oil. Biological activities such as antibacterial and antioxidant activity possibly allied with total phenolic content. The strong antioxidant activity of MAHD extracted essential oil is related to its higher phenolic content i.e. 1, 8-cineol[24][33].

\section{Conclusion}

In this study, the composition and yield of essential oil of Amomum subulatum were varied with the extraction methods. Microwave assisted hydrodistillation requires the significantly shorter time of extraction than 
conventional hydrodistillation method. The energy requirement is lesser in case of MAHD than traditional methods. This study also highlights that MAHD method is advantageous to recover more oxygenated monoterpenes (1, 8-cineol, Terpinen-4-ol and $\alpha$-terpineol). However, the hydrocarbon monoterpenes such as $\alpha$-pinene and $\beta$-pinene have a lower percentage of MAHD extract. Antibacterial activity of essential oil obtained by MAHD method is greater than HD. against both the studied microorganisms viz. Staphylococcus aureus and E. coli. Radical scavenging activity (DPPH) of both essential oils was good but essential oil extracted by MAHD showing better results.

Conflict of Interest : The authors declare that they have no conflict of interest.References

1. Rout PK, Sahoo D, Jena KS, Rao YR (2003) Analysis of the Oil of Large Cardamom ( Amomum subulatum Roxb.,) Growing in Sikkim. J Essent Oil Res 15:265-266. https://doi.org/10.1080/10412905.2003.9712138

2. Gilani; SR, Shahid; I, Mehmud; MJS, Ahme R (2006) Antimicrobial activities and physico chemical properties Antimicrobial Activities and Physico-Chemical Properties of the Essential Oil from Amomum Subulatum. Int J Appl Chem 2:81-86

3. Rao YS, Kumar A, Chatterjee S, et al (1993) Large cardamom ( Amomum subulatum Roxb .) -a review. J Spices Aromat Crop 2 1-15

4. Agnihotri S, Wakode S (2010) Antimicrobial activity of essential oil and various extracts of fruits of greater cardamom. Indian J. Pharm. Sci. 72:657-659

5. Bhatt M, Juyal V, Singh A (2014) Amomum Subulatum Roxb : A Critical Review of Pharmacological and Phytochemical Data. Int J Pharm Phytopharm Res 3:362-364

6. Verma SK, Jain V, Singh DP (2012) Effect of Greater cardamom (Amomum subulatum Roxb.) on blood lipids, fibrinolysis and total antioxidant status in patients with ischemic heart disease. Asian Pacific J Trop Dis 2:739-743. https://doi.org/10.1016/S2222-1808(12)60255-2

7. Berka-Zougali B, Ferhat MA, Hassani A, et al (2012) Comparative study of essential oils extracted from Algerian myrtus communis L. leaves using microwaves and hydrodistillation. Int J Mol Sci 13:4673-4695. https://doi.org/10.3390/ijms13044673

8. Bag A, Chattopadhyay RR (2015) Evaluation of synergistic antibacterial and antioxidant efficacy of essential oils of spices and herbs in combination. PLoS One 10:1-17. https://doi.org/10.1371/journal.pone.0131321

9. Gurudutt KN, Naik JP, Srinivas P, Ravindranath B (1996) Volatile constituents of large cardamom (Amomum subulatum Roxb.). Flavour Fragr J 11:7-9. https://doi.org/10.1002/(SICI)1099-1026(199601)11:1<7::AIDFFJ542>3.0.CO;2-9

10. Naik JP, Rao LJM, Kumar TMM, Sampathu SR (2004) Chemical composition of the volatile oil from the pericarp (husk) of large cardamom (Amomum subulatum Roxb.). Flavour Fragr J 19:441-444. https://doi.org/10.1002/ffj.1336

11. Kaskoos RA, Mir SR, Kapoor R, Ali M (2008) Essential Oil Composition of the Fruits of Amomum subulatum Roxb. J Essent Oil Bear Plants 11:184-187. https://doi.org/10.1080/0972060X.2008.10643617

12. Bajpai VK, Sharma A, Kim SH, Baek K-H (2015) Chemical Composition, Antioxidant, Lipid Peroxidation Inhibition and Free Radical Scavenging Activities of Microwave Extracted Essential Oil from Allium sativum. J Essent Oil Bear Plants 18:300-313. https://doi.org/10.1080/0972060X.2013.764215

13. Mandal V, Mohan Y, Hemalatha S (2007) Microwave Assisted Extraction - An Innovative and Promising Extraction Tool for Medicinal Plant Research. Pharmacogn Rev 1:7-18

14. Cardoso-Ugarte GA, Juárez-Becerra GP, Sosa-Morales ME, López-Malo A (2013) Microwave-assisted extraction of essential oils from herbs. J Microw Power Electromagn Energy 47:63-72 
15. Kormin F, Ahmed I, Yunus RM, Yusof ZAM (2010) The potential of modified microwave extraction system (mmes) to extract bioactive components from ferns. Int J Eng Technol 10:7-21

16. Li X-J, Wang W, Luo M, et al (2012) Solvent-free microwave extraction of essential oil from Dryopteris fragrans and evaluation of antioxidant activity. Food Chem 133:437-444. https://doi.org/10.1016/j.foodchem.2012.01.056

17. Chan C-H, Yusoff R, Ngoh G-C, Kung FW-L (2011) Microwave-assisted extractions of active ingredients from plants. J Chromatogr A 1218:6213-6225. https://doi.org/10.1016/j.chroma.2011.07.040

18. Li Y, Fabiano-Tixier AS, Vian MA, Chemat F (2013) Solvent-free microwave extraction of bioactive compounds provides a tool for green analytical chemistry. Trends Anal Chem 47:1-11. https://doi.org/10.1016/j.trac.2013.02.007

19. Golmakani M-T, Rezaei K (2008) Comparison of microwave-assisted hydrodistillation withthe traditional hydrodistillation method in the extractionof essential oils from Thymus vulgaris L. Food Chem 109:925-930. https://doi.org/10.1016/j.foodchem.2007.12.084

20. M. R, Nour AH, Sulaiman ZA, et al (2014) A Comparative Study of Lemongrass (Cymbopogon Citratus) Essential Oil Extracted by Microwave-Assisted Hydrodistillation (MAHD) and Conventional Hydrodistillation (HD) Method. Int J Chem Eng Appl 5:104-108. https://doi.org/10.7763/IJCEA.2014.V5.360

21. Chen X, Zhang Y, Zu Y, et al (2011) Composition and biological activities of the essential oil from Schisandra chinensis obtained by solvent-free microwave extraction. LWT - Food Sci Technol 44:2047-2052. https://doi.org/10.1016/j.lwt.2011.05.013

22. Bhalerao MS, Patwardhan A V., Bhosale MA, et al (2016) Epoxidised soybean oil-Cu/Cu 2 O bionanocomposite material: synthesis and characterization with antibacterial activity. RSC Adv 6:38906-38912. https://doi.org/10.1039/C6RA00588H

23. I.P.S Kapoor , B. Singh , G. Singh , V. Isidorov LS (2008) Chemistry, antifungal and antioxidant activities of cardamom (Amomum subulatum) essential oil and oleoresins. Int J Essent Oil Ther 2:29-40

24. Abdelhady MI, Aly HAH (2012) Antioxidant antimicrobial activities of callistemon comboynensis essential oil. Free Radicals Antioxidants 2:37-41. https://doi.org/10.5530/ax.2012.2.8

25. Shekhar TC, Anju G (2014) Antioxidant Activity by DPPH Radical Scavenging Method of Ageratum conyzoides Linn. Leaves. Am J Ethnomedicine 1:244-249

26. Bousbia N, Abert Vian M, Ferhat MA, et al (2009) Comparison of two isolation methods for essential oil from rosemary leaves: Hydrodistillation and microwave hydrodiffusion and gravity. Food Chem 114:355-362. https://doi.org/10.1016/j.foodchem.2008.09.106

27. Desai MA, Parikh J (2012) Microwave Assisted Extraction of Essential Oil From Cymbopogon Flexuosus (Steud.) Wats.: A Parametric and Comparative Study. Sep Sci Technol 47:1963-1970. https://doi.org/10.1080/01496395.2012.

28. Ferhat MA, Meklati BY, Smadja J, Chemat F (2006) An improved microwave Clevenger apparatus for distillation of essential oils from orange peel. J Chromatogr A 1112:121-126. https://doi.org/10.1016/j.chroma.2005.12.030

29. Lucchesi ME, Smadja J, Bradshaw S, et al (2007) Solvent free microwave extraction of Elletaria cardamomum L.: A multivariate study of a new technique for the extraction of essential oil. J Food Eng 79:1079-1086. https://doi.org/10.1016/j.jfoodeng.2006.03.029

30. Erkan N, Ayranci G, Ayranci E (2008) Antioxidant activities of rosemary (Rosmarinus Officinalis L.) extract, blackseed (Nigella sativa L.) essential oil, carnosic acid, rosmarinic acid and sesamol. Food Chem 110:76-82. https://doi.org/10.1016/j.foodchem.2008.01.058

31. Chen Z, Bertin R, Froldi G (2013) EC50 estimation of antioxidant activity in DPPH* assay using several statistical programs. Food Chem 138:414-420. https://doi.org/10.1016/j.foodchem.2012.11.001

32. Kulisic T, Radonic A, Katalinic V, Milos M (2004) Use of different methods for testing antioxidative activity of oregano essential oil. Food Chem 85:633-640. https://doi.org/10.1016/j.foodchem.2003.07.024 
33. Wojdyło A, Oszmiański J, Czemerys R (2007) Antioxidant activity and phenolic compounds in 32 selected herbs. Food Chem 105:940-949. https://doi.org/10.1016/j.foodchem.2007.04.038

List of tables

Table 1: Chemical composition of essential oils extracted by hydrodistillation (HD) and Microwave assisted hydrodistillation (MAHD) from Amomum subulatum seeds

\begin{tabular}{llll}
\hline NAME OF COMPOUND & MAW & HD & RI \\
\hline$\alpha$-pinene & 2.40 & 4.03 & 937 \\
$\beta$-pinene & 3.71 & 4.55 & 974 \\
1,8 -cineole & 89.62 & 88.75 & 1031 \\
Terpinen-4-ol & 1.42 & 1.21 & 1183 \\
$\alpha$-terpineol & 3.10 & 1.50 & 1178 \\
\hline
\end{tabular}

Table 2: Antioxidant activity (Percent Inhibition) of essential oil in DPPH free radical scavenging activity

\begin{tabular}{llll}
\hline Method /cons & \% Inhibition & \% Inhibition & \\
& MAHD & HD & AA \\
10 & 54.43 & 47.44 & 95.18 \\
15 & 58.44 & 50.98 & 96.26 \\
20 & 69.71 & 60.34 & 96.34 \\
25 & 74.44 & 64.84 & 96.66 \\
\hline
\end{tabular}

Where AA is Ascorbic Acid

\section{Figure Ligand}

1. Figure 1 Schematic of the fabricated microwave and assembly used in this study

2. Figure 2 Influence of microwave power on essential oil yield

3. Figure 3 Influence of extraction time on essential oil yield

4. Figure 4 Influence of temperature on essential oil yield

5. Figure 5 Antibacterial activities of a: HD essential oil against E-coli b: HD essential oil against S. aureus c: MAHD essential oil against E-coli and d: MAHD essential oil against S. aureus

6. Figure 6 Zone of inhibition of MAHD and HD extracted essential oil against Escherichia coli and Staphylococcus aureus bacteria

7. Figure 7 Plot of percentage of DPPH radical scavenging capacity against the concentration of essential oils By MAHD and HD methods

\section{Hosted file}

Figures.docx available at https://authorea.com/users/307042/articles/438033-chemical-compositionantibacterial-and-antioxidant-activity-of-the-essential-oils-of-amomum-subulatum-by-usingmicrowave-extraction-comparison-with-hydro-distillation 